\title{
INCLUSÃO E AS ATITUDES SOCIAIS DOS ALUNOS: A IMPORTÂNCIA DA INTERVENÇÃO
}

\author{
Aline de Novaes Conceição \\ Universidade Estadual Paulista - UNESP, Programa de Pós-Graduação em Educação, Marília, SP. E-mail: \\ alinenovaesc@gmail.com.
}

\begin{abstract}
RESUMO
Todos devem ter a possibilidade de acesso a tudo que precisarem independentemente do seu estado de saúde, etnia, classe social, deficiência, habilidade ou quaisquer outras diferenças e diversidades. Não havendo a rejeição do diferente, compreendendo a diversidade humana como enriquecimento social. A partir disso, com o objetivo de analisar as mudanças de atitudes sociais de alunos sem deficiência em relação a inclusão após a aplicação de um programa informativo sobre o tema, selecionou-se uma turma de terceiro ano do Ensino Fundamental de uma Escola Municipal do interior do estado de São Paulo e aplicou-se com eles a Escala Infantil de Atitudes Sociais em relação à Inclusão. Após isso, realizou-se uma intervenção a partir de um programa informativo infantil e aplicou-se novamente a escala. Verificou-se que as atitudes sociais dos alunos sem deficiência em relação a inclusão, podem ser alteradas positivamente a partir de intervenção realizada com um programa informativo.
\end{abstract}

Palavras-chave: educação, inclusão, alunos e inclusão, atitudes sociais, intervenção.

\section{INCLUSION AND THE SOCIAL ATTITUDES OF STUDENTS: THE IMPORTANCE OF THE INTERVENTION}

\begin{abstract}
Everyone should have access to everything you need regardless of your state of health, ethnicity, social class, disabilities, ability or any other differences and Diversities. There is no rejection of different, understanding human diversity as enrichment. Thus, in order to analyze the changes of social attitudes of students without disabilities as for inclusion after applying an informative program on the subject, have chosen a group of third grade to a Municipal school in the State of São Paulo and applied them to child scale of social attitudes regarding inclusion. After that, a program of news and to apply intervention. We found that they can modified positively social attitudes of students without disabilities in relation to the inclusion of intervention carried out an informative program.
\end{abstract}

Keywords: education, inclusion, pupils and inclusion, social attitudes, intervention. 


\section{INTRODUÇÃO}

Todos devem ter a possibilidade de acesso a tudo que quiserem e precisarem, independentemente do seu estado de saúde, etnia, classe social, deficiência, habilidade ou quaisquer outras diferenças e diversidades. Não havendo a rejeição do diferente, compreendendo a diversidade humana como enriquecimento social, percebendo o sujeito nas suas singularidades e visando o rompimento universal de barreiras, inclusive as atitudinais.

Visando atender alguns desses públicos, na área educacional, têm-se a Educação Especial que está contida na Educação Inclusiva, visto que enfoca um grupo dentre a enorme diversidade de grupos que erroneamente por determinadas características são excluídos da sociedade. Nesse grupo da Educação Especial, está o denominado "público-alvo" que é definido na legislação brasileira da seguinte forma: alunos com deficiência, transtornos globais do desenvolvimento e altas habilidades/superdotação (BRASIL, 2009).

A Educação Especial consiste em proporcionar ferramentas e recursos para que os alunos que têm Necessidades Educacionais Especiais aprendam e para que se desenvolvam. Essa educação perpassa todas as modalidades de ensino e deve ter medidas de apoios efetivas, visando garantir a participação integral e bem-sucedida dos alunos na programação escolar.

$\mathrm{Na}$ Educação Especial é considerado que todos podem aprender independentemente das suas diferenças. Souza (2014) menciona que é importante que se tenham estudos sobre a maneira que as pessoas se relacionam com essas diferenças.

Considerando que ao se pensar nas diferenças, é importante considerar que a deficiência deve ser compreendida também como decorrente do grupo social, pois "[...] para a devida compreensão das deficiências, é necessário estudar também as reações de pessoas nãodeficientes face aos deficientes." (OMOTE, 1994, p. 70).

Com isso, para compreender a construção social da deficiência, é necessário considerar as atitudes dos sujeitos. Considerando que a deficiência deve ser analisada a partir de uma perspectiva social e cultural e que uma das "[...] únicas alegações que se pode fazer a respeito do conceito de deficiência é de que ele ainda não está definido, para a sociedade em geral, de maneira consistente devido à ausência de consenso." (SOUZA, 2014, p. 36).

A partir disso, o objetivo da pesquisa consiste em analisar as mudanças de atitudes sociais de alunos sem deficiência em relação a inclusão após a aplicação de um programa informativo sobre o tema.

\section{METODOLOGIA}

Como procedimento metodológico da pesquisa, a fim de contemplar o objetivo, selecionou-se uma turma de terceiro ano dos anos iniciais do Ensino Fundamental de uma Escola Municipal localizada em uma cidade do interior do estado de São Paulo, que atende predominantemente alunos em situação de vulnerabilidade social.

Essa escola atende do 10 ao 5o ano do Ensino Fundamental (6 a 10 anos), em período integral, ou seja, os alunos têm aulas das $7 \mathrm{~h}$ às $16 \mathrm{~h}$, sendo que neste ano de 2017 , na escola há dois primeiros anos, dois segundos anos, três terceiros anos, três quartos anos e três quintos anos. Participaram da pesquisa 18 alunos com idade entre 8 a 9 anos, sendo 10 do gênero masculino e 8 do gênero feminino.

Para obter-se os dados utilizou-se a Escala Infantil de Atitudes Sociais em relação à Inclusão, utilizada por Souza (2014) e que teve como base Baleotti (2006), essa escala contém 20 enunciados sendo $10 \mathrm{com}$ atitudes sociais favoráveis em relação à inclusão e outros $10 \mathrm{com}$ desfavoráveis.

Cada enunciado é constituído de três alternativas "sim", "não" e "não sei". Os alunos escolheram uma alternativa para cada enunciado, inserindo um " $X$ " na lacuna ao lado das três alternativas. 
Após isso, realizou-se uma intervenção a partir de um programa informativo infantil elaborado por Vieira (2014) e apresentado em sua tese, o programa é composto de 10 encontros e visa informar as crianças sobre diversidade, deficiências (auditiva, visual, física e múltiplas, intelectual, Síndrome de Down) e inclusão, a partir, principalmente, de conversas, vídeos, jogos, livros, fantoches e imagens. Os encontros foram realizados uma vez na semana.

Em seguida, aplicou-se novamente a Escala Infantil de Atitudes Sociais em relação à Inclusão, utilizada por Souza (2014).

A fim de análise, realizou-se tabulação dos dados calculando os escores somando-se algebricamente os pontos obtidos, que foram atribuídos da seguinte forma: -1 quando o respondente discorda do enunciado favorável à inclusão ou concorda com o enunciado desfavorável à inclusão; 1 quando o respondente concorda com o enunciado favorável à inclusão ou discorda do enunciado desfavorável à inclusão; e 0 quando o respondente assinala que não sabe opinar a respeito do conteúdo do enunciado.

A pesquisa respeitou todas as normas estabelecidas pela resolução no 466/2012 (BRASIL, 2012), referentes aos aspectos éticos em pesquisa com seres humanos e foi realizada após a aprovação pelo Comitê de Ética em Pesquisa com Seres Humanos (CEP) cujo número do comprovante de envio do projeto de pesquisa é $033424 / 2017$. Todos os responsáveis pelos alunos participantes da pesquisa receberam e assinaram um Termo de Consentimento Livre e esclarecido.

\section{RESULTADOS}

Após ser aplicada a escala infantil, como mencionado, atribuiu-se valores as respostas fornecidas pelos alunos. A escala contém 20 perguntas o que significa que a pontuação máxima positiva poderia ser 360 e a pontuação mínima negativa poderia ser -360, visto que 18 participantes responderam as questões.

Com a primeira aplicação a turma participante atingiu um total de cinco pontos como se vê no Quadro 1, abaixo:

Quadro 1. Pontuação da primeira aplicação da Escala Infantil de Atitudes Sociais

\begin{tabular}{|c|c|c|c|}
\hline $\begin{array}{c}\text { Enunciados } \\
\text { favoráveis a } \\
\text { inclusão }\end{array}$ & Pontuação da turma & $\begin{array}{c}\text { Enunciados } \\
\text { desfavoráveis a } \\
\text { inclusão }\end{array}$ & $\begin{array}{c}\text { Pontuação da } \\
\text { turma }\end{array}$ \\
\hline 3 & 4 & 1 & 3 \\
\hline 4 & -6 & 2 & 2 \\
\hline 6 & -2 & 5 & -14 \\
\hline 7 & 7 & 8 & -6 \\
\hline 9 & 1 & 11 & -13 \\
\hline 10 & 3 & 12 & 3 \\
\hline 15 & 12 & 13 & 1 \\
\hline 16 & -2 & 14 & 6 \\
\hline 18 & 7 & 17 & 1 \\
\hline 20 & -3 & 19 & 1 \\
\hline TOTAL & 21 & TOTAL & -16 \\
\hline \multicolumn{4}{|c|}{ 21-16 = 5 pontos } \\
\hline
\end{tabular}

Fonte: elaboração própria.

De acordo com o Quadro 1 acima, é possível constatar que os enunciados que atingiram mais respostas negativas foram o 4 (-6 pontos), o 5 (-14 pontos) e o 11 (-13 pontos).

O enunciado 4, era: "OS ALUNOS SURDOS DEVEM ESTUDAR EM CLASSE JUNTO COM ALUNOS NORMAIS. ". O enunciado 5, era: "O ALUNO COM DEFICIÊNCIA SEMPRE PRECISA DE 
AJUDA NA SALA DE AULA". O enunciado 11, era: "A PROFESSORA DEVE DAR MAIS ATENÇÃO A TODOS OS ALUNOS COM DEFICIÊNCIA. ".

De acordo com o Quadro 1 acima, é possível constatar que os enunciados que atingiram mais respostas positivas foram o 14 (6 pontos), o 15 (12 pontos) e o 18 (7 pontos).

O enunciado 14, era: "OS ALUNOS NORMAIS DEVEM RECLAMAR QUANDO SOUBEREM QUE EM SUA CLASSE VAI ESTUDAR UM ALUNO COM DEFICIÊNCIA". O enunciado 15, era: "EU GOSTO DE AJUDAR UM ALUNO COM DEFICIÊNCIA NA SALA DE AULA". O enunciado 18, era: "O ALUNO COM DEFICIÊNCIA TEM AMIZADE COM OS OUTROS ALUNOS DA CLASSE".

Após a aplicação do programa informativo infantil, aplicou-se novamente a escala e obteve-se os resultados abaixo:

Quadro 2. Pontuação da segunda aplicação da Escala Infantil de Atitudes Sociais

\begin{tabular}{|c|c|c|c|}
\hline $\begin{array}{l}\text { Respostas } \\
\text { favoráveis }\end{array}$ & Pontuação da turma & $\begin{array}{l}\text { Respostas } \\
\text { Desfavoráveis }\end{array}$ & $\begin{array}{l}\text { Pontuação da } \\
\text { turma }\end{array}$ \\
\hline 3 & 14 & 1 & 5 \\
\hline 4 & 12 & 2 & 8 \\
\hline 6 & 11 & 5 & -14 \\
\hline 7 & 16 & 8 & 10 \\
\hline 9 & 12 & 11 & 15 \\
\hline 10 & -6 & 12 & 14 \\
\hline 15 & 15 & 13 & 12 \\
\hline 16 & 12 & 14 & 5 \\
\hline 18 & 18 & 17 & 4 \\
\hline 20 & 10 & 19 & $\mathbf{6 8}$ \\
\hline TOTAL & $\mathbf{1 1 4}$ & TOTAL & \\
\hline TOTAL DA TURMA & $\mathbf{1 1 4 + 6 8 = 1 8 2}$ pontos &
\end{tabular}

Fonte: elaboração própria.

De acordo com o Quadro 2 acima, é possível constatar que os únicos enunciados que tiveram respostas negativas foram o 5 (-14) e o 10 (-6 pontos). 05 , foi mencionado acima e o enunciado 10 era: "AS CLASSES SÓ PARA ALUNOS COM DEFICIÊNCIA DEVERIAM ACABAR".

Dessa forma, constata-se que o enunciado 5 teve valor negativo em ambas as aplicações.

De acordo com o Quadro 2 acima, é possível constatar que os enunciados que tiveram mais respostas positivas foram o 11 (15 pontos), o 15 (15 pontos) e o 18 (18 pontos). O enunciado 11, era: "A PROFESSORA DEVE DAR MAIS ATENÇÃO A TODOS OS ALUNOS COM DEFICIÊNCIA" e o 15 foi mencionado acima.

\section{DISCUSSÃO}

No Quadro 1, os alunos atingiram a pontuação 5, enquanto que no Quadro 2, atingiram a pontuação 182. Houve um aumento significativo de pontuação positiva de atitudes sociais em relação à Inclusão, o que demonstra a importância de aplicação para os alunos de um programa informativo infantil sobre inclusão.

Vieira (2006) aplicou um programa informativo infantil sobre deficiência intelectual e após analisar os conteúdos das entrevistas realizadas com 40 alunos de duas turmas de um 20 ano do Ensino Fundamental constatou que o programa proporcionou um entendimento maior sobre a aceitação social dessa deficiência.

Souza (2014) demonstra a importância de descrever as concepções dos envolvidos no espaço escolar sobre a deficiência e demonstra também a dificuldade de se relacionar as concepções e as atitudes, todavia reconhece que há relação. 
Vieira (2015) demonstra a possibilidade de trabalhar com um grupo controle e a maneira que um programa informativo pode interferir no entendimento sobre as deficiências.

Dessa forma, na educação, é necessário que haja programas informativos infantis sobre a inclusão a fim de que alterem as concepções dos sujeitos sobre a inclusão e diversidade e assim alterem as atitudes sociais desses sujeitos sobre o tema. Compreendendo que as concepções indiciam atitudes.

\section{CONSIDERAÇÕES FINAIS}

As atitudes sociais dos alunos sem deficiência em relação a inclusão, podem ser alteradas positivamente a partir de intervenção realizada com um programa informativo, que, além de contribuir com as concepções dos alunos, também contribui com as dos professores que aplicam o programa.

É necessário que haja a reflexão sobre os resultados da aplicação dos programas informativos infantis, a fim de verificar o que é necessário informar com mais ênfase para cada turma, pois verificou-se que os alunos participantes precisavam de mais informações sobre os alunos com deficiência e a sala de aula.

Compreendendo que os alunos com deficiência nem sempre precisam de ajuda na sala de aula e considerando que as classes em que há somente alunos com deficiências deveriam acabar, a fim de que haja a inclusão desses alunos e assim haja o convívio com o diferente.

Convívio que deve ser permeado de atitudes sociais positivas em relação a inclusão, incentivando iniciativas de comunicação e amizade e sentimentos de cooperação com esses sujeitos.

\section{REFERÊNCIAS}

BALEOTTI, Luciana Ramos. Um estudo do ambiente educacional inclusivo: descrição das atitudes sociais em relação à inclusão e das relações interpessoais. 2006. 183 f. Tese (Doutorado em Educação) - Faculdade de Filosofia e Ciências, Universidade Estadual Paulista, Marília, 2006.

BRASIL. MINISTÉRIO DA EDUCAÇÃO CONSELHO NACIONAL DE EDUCAÇÃO, CÂMARA DE EDUCAÇÃO BÁSICA. Institui Diretrizes Operacionais para o Atendimento Educacional Especializado na Educação Básica, modalidade Educação Especial, Resolução n. 4, de 2 de outubro de 2009. Brasília, seção 1, p. 17, 2009.

BRASIL. CONSELHO NACIONAL DE SAÚDE (BRASIL). Resolução $\mathbf{n}^{\mathbf{0}} \mathbf{4 6 6}$, de 12 de dezembro de 2012. Brasília, 2012. Disponível em: <http://conselho.saude.gov.br/resolucoes/2012/Reso466.pdf >. Acesso em 10 jan. 2012.

OMOTE, Sadao. Deficiência e não-deficiência: recortes do mesmo tecido. Revista Brasileira de Educação Especial, v.1, p. 65-73, 1994.

SOUZA, Maewa Martina Gomes da Silva E. Estudo evolutivo de concepções de crianças e adolescentes sem deficiência sobre as deficiências e suas atitudes sociais em relação à inclusão. 2014. 132f. Dissertação (Mestrado em Educação)-Universidade Estadual Paulista, Faculdade de Filosofia e Ciências, Marília, 2014.

VIEIRA, Camila Mugnai. Programa informativo sobre deficiência mental e inclusão: efeitos nas atitudes e concepções de crianças não-deficientes. 2006. 209 f. Dissertação (Mestrado em Ciências Humanas)-Universidade Federal de São Carlos, São Carlos, 2006. 
Atitudes sociais em relação à inclusão: efeitos da capacitação de professores para ministrar programa informativo aos alunos. 2014. 183 f. Tese (Doutorado em Ciências Humanas)Universidade Estadual Paulista, Faculdade de Filosofia e Ciências, Marília, 2014.

Sentimentos infantis em relação à deficiência intelectual: efeitos de uma intervenção. Psicologia ciência e profissão, no 35, p. 423-436, 2015. 